\title{
Online education in the post-COVID era
}

\author{
The coronavirus pandemic has forced students and educators across all levels of education to rapidly adapt to \\ online learning. The impact of this - and the developments required to make it work - could permanently change \\ how education is delivered.
}

\section{Barbara B. Lockee}

\section{I} he COVID-19 pandemic has forced the world to engage in the ubiquitous use of virtual learning. And while online and distance learning has been used before to maintain continuity in education, such as in the aftermath of earthquakes ${ }^{1}$, the scale of the current crisis is unprecedented. Speculation has now also begun about what the lasting effects of this will be and what education may look like in the post-COVID era. For some, an immediate retreat to the traditions of the physical classroom is required. But for others, the forced shift to online education is a moment of change and a time to reimagine how education could be delivered ${ }^{2}$.

\section{Looking back}

Online education has traditionally been viewed as an alternative pathway, one that is particularly well suited to adult learners seeking higher education opportunities. However, the emergence of the COVID-19 pandemic has required educators and students across all levels of education to adapt quickly to virtual courses. (The term 'emergency remote teaching' was coined in the early stages of the pandemic to describe the temporary nature of this transition ${ }^{3}$.) In some cases, instruction shifted online, then returned to the physical classroom, and then shifted back online due to further surges in the rate of infection. In other cases, instruction was offered using a combination of remote delivery and face-to-face: that is, students can attend online or in person $\left(\right.$ referred to as the HyFlex model $\left.{ }^{4}\right)$. In either case, instructors just had to figure out how to make it work, considering the affordances and constraints of the specific learning environment to create learning experiences that were feasible and effective.

The use of varied delivery modes does, in fact, have a long history in education. Mechanical (and then later electronic) teaching machines have provided individualized learning programmes since the 1950s and the work of B. F. Skinner ${ }^{5}$, who proposed using technology to walk individual learners through carefully designed sequences of instruction with

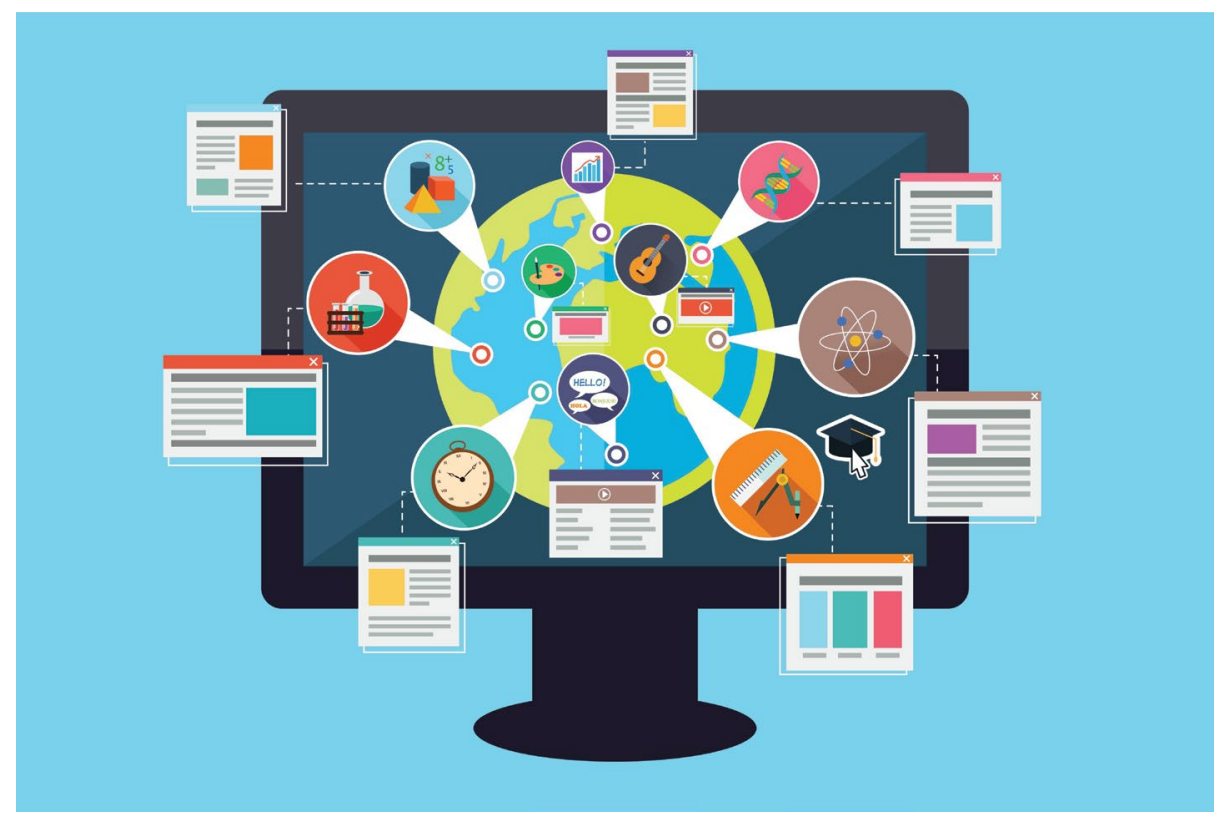

Credit: Artisticco LLC / Alamy Stock Vector

immediate feedback indicating the accuracy of their response. Skinner's notions formed the first formalized representations of programmed learning, or 'designed' learning experiences. Then, in the 1960s, Fred Keller developed a personalized system of instruction ${ }^{6}$, in which students first read assigned course materials on their own, followed by one-on-one assessment sessions with a tutor, gaining permission to move ahead only after demonstrating mastery of the instructional material. Occasional class meetings were held to discuss concepts, answer questions and provide opportunities for social interaction. A personalized system of instruction was designed on the premise that initial engagement with content could be done independently, then discussed and applied in the social context of a classroom.

These predecessors to contemporary online education leveraged key principles of instructional design - the systematic process of applying psychological principles of human learning to the creation of effective instructional solutions - to consider which methods (and their corresponding learning environments) would effectively engage students to attain the targeted learning outcomes. In other words, they considered what choices about the planning and implementation of the learning experience can lead to student success. Such early educational innovations laid the groundwork for contemporary virtual learning, which itself incorporates a variety of instructional approaches and combinations of delivery modes.

\section{Online learning and the pandemic} Fast forward to 2020, and various further educational innovations have occurred to make the universal adoption of remote learning a possibility. One key challenge is access. Here, extensive problems remain, including the lack of Internet connectivity in some locations, especially rural ones, and the competing needs among family members for the use of home technology. However, creative solutions have emerged to provide students and families with the 
facilities and resources needed to engage in and successfully complete coursework ${ }^{7}$. For example, school buses have been used to provide mobile hotspots, and class packets have been sent by mail and instructional presentations aired on local public broadcasting stations. The year 2020 has also seen increased availability and adoption of electronic resources and activities that can now be integrated into online learning experiences. Synchronous online conferencing systems, such as Zoom and Google Meet, have allowed experts from anywhere in the world to join online classrooms ${ }^{8}$ and have allowed presentations to be recorded for individual learners to watch at a time most convenient for them. Furthermore, the importance of hands-on, experiential learning has led to innovations such as virtual field trips and virtual labs ${ }^{9}$. A capacity to serve learners of all ages has thus now been effectively established, and the next generation of online education can move from an enterprise that largely serves adult learners and higher education to one that increasingly serves younger learners, in primary and secondary education and from ages 5 to 18 .

The COVID-19 pandemic is also likely to have a lasting effect on lesson design. The constraints of the pandemic provided an opportunity for educators to consider new strategies to teach targeted concepts. Though rethinking of instructional approaches was forced and hurried, the experience has served as a rare chance to reconsider strategies that best facilitate learning within the affordances and constraints of the online context. In particular, greater variance in teaching and learning activities will continue to question the importance of 'seat time' as the standard on which educational credits are based ${ }^{10}$ - lengthy Zoom sessions are seldom instructionally necessary and are not aligned with the psychological principles of how humans learn. Interaction is important for learning but forced interactions among students for the sake of interaction is neither motivating nor beneficial.

While the blurring of the lines between traditional and distance education has been noted for several decades ${ }^{11}$, the pandemic has quickly advanced the erasure of these boundaries. Less single mode, more multi-mode (and thus more educator choices) is becoming the norm due to enhanced infrastructure and developed skill sets that allow people to move across different delivery systems ${ }^{12}$. The well-established best practices of hybrid or blended teaching and learning ${ }^{13}$ have served as a guide for new combinations of instructional delivery that have developed in response to the shift to virtual learning. The use of multiple delivery modes is likely to remain, and will be a feature employed with learners of all ages ${ }^{14,15}$. Future iterations of online education will no longer be bound to the traditions of single teaching modes, as educators can support pedagogical approaches from a menu of instructional delivery options, a mix that has been supported by previous generations of online educators ${ }^{16}$.

Also significant are the changes to how learning outcomes are determined in online settings. Many educators have altered the ways in which student achievement is measured, eliminating assignments and changing assessment strategies altogether ${ }^{17}$. Such alterations include determining learning through strategies that leverage the online delivery mode, such as interactive discussions, student-led teaching and the use of games to increase motivation and attention. Specific changes that are likely to continue include flexible or extended deadlines for assignment completion ${ }^{18}$, more student choice regarding measures of learning, and more authentic experiences that involve the meaningful application of newly learned skills and knowledge ${ }^{19}$, for example, team-based projects that involve multiple creative and social media tools in support of collaborative problem solving.

\section{Outlook}

In response to the COVID-19 pandemic, technological and administrative systems for implementing online learning, and the infrastructure that supports its access and delivery, had to adapt quickly. While access remains a significant issue for many, extensive resources have been allocated and processes developed to connect learners with course activities and materials, to facilitate communication between instructors and students, and to manage the administration of online learning. Paths for greater access and opportunities to online education have now been forged, and there is a clear route for the next generation of adopters of online education.

Before the pandemic, the primary purpose of distance and online education was providing access to instruction for those otherwise unable to participate in a traditional, place-based academic programme. As its purpose has shifted to supporting continuity of instruction, its audience, as well as the wider learning ecosystem, has changed. It will be interesting to see which aspects of emergency remote teaching remain in the next generation of education, when the threat of COVID-19 is no longer a factor. But online education will undoubtedly find new audiences. And the flexibility and learning possibilities that have emerged from necessity are likely to shift the expectations of students and educators, diminishing further the line between classroom-based instruction and virtual learning.

\section{Barbara B. Lockee}

School of Education, Virginia Tech, Blacksburg, VA, USA.

$\bigotimes_{e-\text { mail:lockeebb@vt.edu }}$

Published online: 25 January 2021

https://doi.org/10.1038/s41928-020-00534-0

References

1. Mackey, J., Gilmore, F., Dabner, N., Breeze, D. \& Buckley, P. J. Online Learn. Teach. 8, 35-48 (2012).

2. Sands, T. \& Shushok, F. The COVID-19 higher education shove. Educause Review https://go.nature.com/302vHbX (16 October 2020).

3. Hodges, C., Moore, S., Lockee, B., Trust, T. \& Bond, M. A. The difference between emergency remote teaching and online learning. Educause Review https://go.nature.com/38084Lh (27 March 2020).

4. Beatty, B. J. (ed.) Hybrid-Flexible Course Design Ch. 1.4 https:// go.nature.com/3o6Sjb2 (EdTech Books, 2019).

5. Skinner, B. F. Science 128, 969-977 (1958).

6. Keller, F. S. J. Appl. Behav. Anal. 1, 79-89 (1968).

7. Darling-Hammond, L. et al. Restarting and Reinventing School: Learning in the Time of COVID and Beyond (Learning Policy Institute, 2020).

8. Fulton, C. Information Learn. Sci. 121, 579-585 (2020).

9. Pennisi, E. Science 369, 239-240 (2020).

10. Silva, E. \& White, T. Change The Magazine Higher Learn. 47, 68-72 (2015)

11. McIsaac, M. S. \& Gunawardena, C. N. in Handbook of Research for Educational Communications and Technology (ed. Jonassen, D. H.) Ch. 13 (Simon \& Schuster Macmillan, 1996).

12. Irvine, V. The landscape of merging modalities. Educause Review https://go.nature.com/2MjiBc9 (26 October 2020).

13. Stein, J. \& Graham, C. Essentials for Blended Learning Ch. 1 (Routledge, 2020).

14. Maloy, R. W., Trust, T. \& Edwards, S. A. Variety is the spice of remote learning. Medium https://go.nature.com/34Y1NxI (24 August 2020)

15. Lockee, B. J. Appl. Instructional Des. https://go.nature. com/3b0ddoC (2020).

16. Dunlap, J. \& Lowenthal, P. Open Praxis 10, 79-89 (2018).

17. Johnson, N., Veletsianos, G. \& Seaman, J. Online Learn. 24, 6-21 (2020).

18. Vaughan, N. D., Cleveland-Innes, M. \& Garrison, D. R. Assessment in Teaching in Blended Learning Environments: Creating and Sustaining Communities of Inquiry (Athabasca Univ. Press, 2013).

19. Conrad, D. \& Openo, J. Assessment Strategies for Online Learning: Engagement and Authenticity (Athabasca Univ. Press, 2018).

\section{Competing interests}

The author declares no competing interests. 